\title{
Civil Society, Nonprofit Organizations, and Citizenship in China: An Editorial Introduction to the China Issue
}

\author{
Taco Brandsen ${ }^{1} \cdot$ Ruth Simsa ${ }^{2}$
}

Published online: 3 August 2016

(C) International Society for Third-Sector Research and The Johns Hopkins University 2016

\section{Background of This Issue}

Since the early 1990s, the size of the Chinese nonprofit sector has gradually increased ( $\mathrm{Yu}$ 2016). It is facing fundamental changes, characterized by rapid growth and a diversification of actors, partly driven by new modes of communication and mobilization. Not surprisingly, the rise of nongovernmental organizations as well as the rise of volunteering in China (Jackson and Adarlo 2014) has attracted a great deal of scholarly attention, not least in this journal. The highly dynamic and complex changes against the background of rapid economic development reflect both the specific conditions of the Chinese system, but are also of relevance beyond the country itself. Although by now the development of the Chinese nonprofit sector has been extensively studied, there are still substantial research gaps, some of which are now being addressed. The environment for such research is not necessarily favorable.

Voluntas gives due credit to this scholarship by publishing an issue focused exclusively on China: its civil society, nonprofit organizations, citizenship, and the institutional environment. This comprises the special issue 'Citizenship in China', as well as a number of independent articles on the Chinese nonprofit and voluntary sector. Together, they show the breadth of current scholarship and the increasing weight of publications on China in the journal. In 2017, there will be a special issue on philanthropy in China.

Taco Brandsen

t.brandsen@fm.ru.nl

1 Radboud University Nijmegen, Nijmegen, The Netherlands

2 Vienna University of Economics and Business, Vienna, Austria 


\section{The Development of the Chinese Nonprofit Sector}

In research on the Chinese civil society, the state-society relationship is often used as a framework for analyzing the effects of the political conditions, the cooperation between government and nonprofit organizations, and international influences on the development of nonprofit organizations. The decisive role of the government for nonprofit organizations' development is the outcome of Chinese history, political culture, and the needs of nonprofit organizations (Yang et al. 2015).

One driving factor of the increase of the nonprofit sector is the reliance of the state on the former's services. The Chinese government needs the assistance of nonprofit organizations in handling environmental problems and thus has created opportunities for environmental nonprofit organizations in China (Yang 2005; Yu 2016) Also, state policies have indirectly created a demand for social organizations, with the state mobilizing nonprofit organizations to alleviate the rising welfare burden (Zhao et al. 2016).

While the regime has discouraged civil society in the past, in general, the government has been found to build local, limited, and issue-based partnerships to increase government's performance and reputation ( $\mathrm{Hu}$ et al. 2016). Zhao et al. summarize an inherent problem in state-civil society relations, namely "... that the Chinese government's current attitude toward non-profits can be summarized as: seek to obtain the benefits of their social service function, mitigate potential dangers that a developed non-profit sector might pose to the system." (Zhao et al. 2016, p. 5)

Consequently, many scholars also point to risks in state-civil society relations, like nonprofit organizations being absorbed into the formal system, the state-being afraid of strong nongovernmental influence-maintaining or increasing control over civil society (Yuanfeng 2015). It has been stated that the state tolerates and even encourages the development of voluntary organizations, as long as they help the government with welfare provision. Generally, Chinese nonprofit organizations face unique challenges from the authoritarian government and its unfriendly nonprofit regulatory system (Zhou 2015a, b). Nevertheless, due to international pressure and civil society activism, the government sometimes seems to respond more openly to people's concerns and to make concessions (Fedorenko and Sun 2015).

While there is hope that civil society may contribute to democratization and participation, nonprofit organizations also face criticism as they operate in closer relationships with the state than would be common for their Western counterparts, within narrow limits defined by the state that tend to restrict dissenting voices (Yang et al. 2014). Civic engagement is encouraged in order to maintain regime stability rather than to increase participation (Yang et al. 2015). Also, recently, nonprofit organizations have faced legitimacy problems due to a series of scandals in the charitable sector. As a result, the public's trust in large charitable organizations has diminished (Zhou and Pan 2016). The majority of nonprofit organizations in China are facing a funding shortage. Private philanthropy is low, and the government constrains nonprofit organizations from raising funds from the general public (Zhou 2015a, b; Zhao et al. 2016). 
Yet, as in many other countries, the nonprofit sector is very heterogeneous, and therefore one should be wary of generalizations. This is also true for the relationship of the state and civil society: the adaptive and fragmented authoritarian system in China has produced unprecedented and unique varieties of state-society relations (Dau and Bräuer 2016). The regulatory system treats organizations with governmental, corporate, and grassroots background differently. Also, the informal nonprofit sector is particularly large, with several millions of organizations operating without registration (Deng 2010; Zhao et al. 2016). There is a wealth of diversity to explore for scholars in our field.

\section{Contributions to This Issue}

The first part of this issue consists of a special issue on Citizenship in China, edited by Dau and Bräuer (2016). Following Migdal's 'state in society' concept, they understand civic engagement as an integral part of state-society relations, which constitute the interplay between state and societal actors, and thus have either mutually empowering or disengaging and alienating effects on both sides. Thus, a basic question for all papers in the special issue is under which conditions the relationship between state and civil society can lead to mutual empowerment. The discussion is based on the notion of a continuity of mechanisms of state control and change of civic engagement, mainly driven by new arenas and new strategies made possible by new media.

After an introduction to the topic and the analysis of continuity and change in China's civic engagement from a 'state in society' perspective by the editors of the special issue, Xiao and Lin (2015) show the influence of historical modes of control on the relations between the state and civil society. They elaborate on path dependencies and show that these relations are continuously becoming more sophisticated. Nevertheless, as the state remains in control of the third sector, the authors see only two choices for third-sector organizations, namely incorporation or provocation.

Wong (2015) discusses advocacy coalitions and policy change in China and analyzes a case of successful conflict solution based on constructive and less confrontational strategies of activists which included local advocacy coalitions.

Two papers deal with the complex relationship of new media and civil society in China. Based on case studies, Wu and Yang (2016) investigate the influence of web 2.0. on political engagement in internet-based civic monitoring of state activities. They highlight the use of new media and its potential in policy monitoring and critiquing, activism for basic rights, and direct participation and governance. By that, they show empowering effects of new media on civil society, especially as new media also enhances the participation of less experienced activists.

Fedorenko and Sun (2015) discuss a strategy of combined provocation of and engagement with government officials applied by the nonprofit sector to address the pressing topic of air pollution. They show how civic engagement in new media might be transformed into concrete outcomes by "stick and carrot" tactics of appreciation and critique, and proactive engagement with the state. Thus, in spite of 
restrictions, environmental activists have found ways to partner with the government and to create more political space.

Based on concepts of advocacy and social movement theory, Stephanie Bräuer presents the analysis of the antidomestic violence movement in Beijing on the background of the discrepancy between official commitment and actual policy outcomes. She shows how civil society is dealing with this sensitive and tabooed topic very creatively by adopting strategies from international contexts, like public art performances. The rationale behind the tactical innovation is analyzed. Also, the paper identifies relations of the mobilizing structure of antidomestic violence organizations and activists. Performing art advocacy is seen as an important addition to previous tactics with the potential to broaden the target group as well as the activist base (Bräuer 2015, p. 22).

In Hua et al. analysis of the famous Wukan protests, the dichotomy of "rights consciousness" and "rules consciousness" is resolved. They argue that protesters used civil rights as a means to realize economic rights-specifically land rights. The authors see the fragmented and heterogeneous character of the Chinese state as a success factor for this campaign. The central government was interested in coopting grassroots civic protest as a means to counterbalance the power of local authorities.

Such forms of state and civil society relationships are not unquestioned. Yang et al. (2015) show in their case study of social management in Hangzhou that increased public participation and the incorporation of civic engagement by the Chinese state have not led to increased democratization. Instead, civil engagement was functionalized to consolidate the current polity by increasing its legitimacy by a so-called logic of "instrument-absorption" Alienation of Civic Engagement in China.

Wang et al. describe relations between trade associations in Shanghai and the government as characterized by cooperative stance from both sides. Based on a longitudinal case study, they show how trade associations have increased their autonomy from the state, thus reaching a level of more effective institutional participation.

The articles in the open part of the issue reflect the diversity of the Chinese civil society and its current developments and challenges.

Huiquan Zhou (2015a) states a research gap regarding the development of individual third-sector organizations, specifically with focus on capacity to achieve their mission. He argues that the vulnerable situation of NPOs that implies especially for grassroots organizations the danger of being kept out of the system, has to be answered by extensive capacity building, not only for securing resources but also to increase legitimacy and irreplaceability. With his examination of a sample of 78 South China grassroots organizations working in the field of rural education promotion, he maps the level of development of grassroots organizations in China. Based on a suggested framework, he assesses and describes the capacity and level of development of this group of voluntary organizations according to the domains products, organizational structure and management, human resource, governance, finance, and marketing. The organizations are further categorized into four different groups: the amateur do-gooders, the start-up charities, the grassroots 
in transition, and the aspiring young organizations. The suggested assessment tool can not only be used for analytical purposes but also to guide organizational capacity building in the future.

The paper by Zhao et al. (2016) contributes to our understanding of service contracting and its impact on NGO development in China. The highly centralized system of social service provision has been criticized for not being cost-efficient or able to meet service needs. Increasingly, service contracting has become popular and is seen as solution for the reform of the country's service provision system and the development of the nonprofit sector. As in many other countries, in China, public funding increasingly is based on service contracts; yet, so far there has not been much research conducted on that topic. Based on empirical research, the article investigates the impact of service contracts on the social service delivery system, the promotion of nonprofit organizations development, and the nature of governmentnonprofit relationship. Positive impacts are found, e.g., with respect to fundraising. However, the authors argue that negative effects are dominating as service contracts are preferably given to nonprofit organizations with strong ties to government, thus increasing social control by the government. While the government is encouraging NPO's service provision role, it is suppressing the civil society role.

Zhiyuan $\mathrm{Yu}$ analyzes the effects of resources, political opportunities, and organizational ecology on the growth trajectories of AIDS nonprofit organizations in China. He integrates theories of collective action and social movements. Based on panel data of AIDS nonprofit organizations from 1994 to 2008, he shows that political opportunity, increased funding, and organizational ecology have positive effects on the growth of AIDS nonprofit organizations. The growth trajectories of grassroots nonprofit organizations, government-organized nonprofit organizations, and international nonprofit organizations are influenced by different factors. The implications not only give into the factors influencing the civil societal sector in relation to HIV/AIDS in China, but also might be important for the future growth of nonprofit organizations in China.

Li (2015) presents a historical analysis of the Red Cross Society in Imperial China during the period 1904-1912. By examining the founding process of the first Chinese Red Cross organization from 1904 to 1912, the key factors in the public and private spheres that contributed to the indigenization of Red Cross are identified. Although philanthropy has a rich tradition in China, few charities were incorporated as independent institutions in the prerevolution era, social welfare was highly centralized and private philanthropy was at the margin. In the later Qing era, modern nonprofit organizations began to emerge. Founded in the Qing era as an answer to severe humanitarian crises, Chinese philanthropists saw the Red Cross model as a pragmatic solution addressing the congruent interest of the imperial court and social elites. By integrating the Chinese tradition of benevolence into the model of institutionalized humanitarian intervention, it contributed to the transformation of traditional charity into modern philanthropy in contemporary China. The trajectory of the Red Cross movement in imperial China supports the synergism perspective of institutional theories (Rathgeb and Gronbjerg 2006). Leadership ties among founders, foreign embassies, and the central government have demonstrated 
the politic and economic effectiveness in the negotiation of support, with support from both the public and private spheres.

In their paper "Beyond the Abolition of Dual Administration: The Challenges to NGO Governance in 21st Century China," Yang et al. (2014) state that the abolition of the dual system that required nonprofit organizations to affiliate with a professional supervisory agency before they could register with the Ministry of Civil Affairs has been the most significant change in China's official policy toward nonprofit organizations since the late 1970s. Also, it can be seen as double-edged sword as it has brought many challenges like funding problems, challenges of selfgovernance. (Yang et al. 2014). These challenges are discussed, and suggestions for new approaches to NGO development are made from the perspective of a partnership between nonprofit organizations and the government, taking into account the need for supportive legislation, the imperative of public trust, and the viability of NGO network organizations.

Ling and Chui (2016) analyze students' willingness for volunteering in Hong Kong. They state that volunteering as well as the demand for volunteers is playing an increasingly bigger role in social services and schools both in Western settings and in the Hong Kong Chinese context and explores the likelihood of the willingness of the students for future volunteering through the lenses of the theory of planned behavior and Personal and Social Responsibility. Based on quantitative research with secondary school students, prior experience in community service is identified as a main predictor of the willingness of the students to participate in future volunteering. It is suggested that, to foster the willingness to volunteer, practitioners should engage students in community service programs. Also, with reference to the results of the study, service design and related arrangements could be improved.

Jackson and Adarlo (2014) also deal with the topic of volunteering in the Chinese context. Based on a survey implemented in 2012, they examine the motivations, experiences, and challenges of the US volunteer teachers in China's Yunnan Province and analyze the challenge volunteers face reconciling cross-cultural views of education while working in postcolonial global contexts. The study points to mismatches of expectations with realities and a lack of cultural competency, which can hinder volunteers in performing their work, cause stress to the volunteers, and negatively impacts their views of their host communities. The biggest challenge is identified in cultural differences in education between the US and Yunnan, China, specifically regarding a lack of student-centered learning in Chinese educational culture. The authors suggest structured assistance for volunteers that might help them to reflect on transnational working conditions and cultural differences, and their interrelated psychological contract and motivations.

Lee and Han (2014) examine relief work of a faith-based organization (FBO) Tzu-Chi (Buddhist Tzu-Chi Compassion Relief Organization)—in China in response to the Malaysia Airlines MH370 incident. The paper shows that crises facilitate a synergetic relationship of coproduction for social services among states, corporate enterprises, and faith-based organizations. The latter deliver services that states and corporate enterprises cannot easily provide. In this particular case study, comparative advantages resulted from transnational networks, moral teachings, and 
compliant political attitude toward the government. The findings underscore the lack of discussion on such organizations in the Chinese civil society literature. Furthermore, they contribute to the understanding of how FBOs may benefit state welfare provisions following a 2012 policy shift in which religion was encouraged to participate in social provision.

Nie et al. (2016) explore factors that influence voluntary disclosure by Chinese foundations. With rising government regulation and social demand for transparency, Chinese foundations have increasingly faced pressure to make their organizations more transparent. Yet, to gain legitimacy, often they react to that development by voluntary disclosing more information than necessary. Based on resource dependence and institutional theories, the article explores what types of information Chinese foundations disclose and how this can be explained. The authors use the database of the China Foundation Centre and show that foundations that depend more on donations, collect more restricted funds, receive fewer government funds, and operate with less government control have a higher probability of offering voluntary disclosure. "Voluntary disclosure is a survival strategy for foundations that rely on donations." (Nie et al. 2016, p. 24). Thus, voluntary disclosure can be a form of self-governance in reaction to resource dependence.

The article by Xu and Liu (2016) focuses on corporate governance of educational foundations on Mainland China and in Taiwan. In spite of substantial differences in the development of foundations in the Mainland and Taiwan, they also share historic and cultural communalities; thus, comparison of these groups of foundations seems to be more promising than comparative models based on the historical and cultural paths of Western foundations. In the comparative study, the authors show that the governance mechanisms of foundations are more important than their governance structures, and that Taiwanese educational foundations are more mature than Mainland foundations with regard to their underlying governance mechanisms. It highlights the importance of effective motivation and training programs for directors and other staff, decision making mechanisms, methods to solve disputes, information disclosure, and awareness of self-discipline.

The next contribution deals with Chinese philanthropic organizations' use of domestic social media. It analyzes activities of rural education nonprofit organizations on Sina Weibo, one of the most popular sites in China, and shows that, despite Internet censorship and the unique relationship with government, Chinese nonprofit organizations are highly active in the web. Their social media usage is both similar to and different from that of their Western counterparts. Regarding functions of social media (information, community, or action), like their Western counterparts, they use social media to share information, build community, and mobilize resources. As they face some unique legitimacy problems, they might have to spend more time and efforts providing information to their stakeholders (Zhou and Pan 2016).

Trying to adapt to changing environments, especially to financial shortages, many organizations use interorganizational cooperative relationships or other forms of cooperation to increase their capabilities and resources. Two papers deal with nonprofit collaboration. 
Chang et al. (2015) employ a qualitative multiple case study to explore relational management mechanisms for strategic nonprofit alliances formed by at least 3 nonprofit organizations of farmers' organizations in Taiwan. The authors suggest that these strategic nonprofit alliances use acceptable cooperative regulations, common standard procedures, strengthen information and communication symmetry, and enforce capability building and corrective measures. Also, the results suggest that alliances should empower partners with deeper input commitment to direct decisions on resource distribution and utilization. If relationships involve low output measurability, the findings point to the effectiveness of heightening partners' voluntary motivation for the common good, with goal achievement assessment measures, professional certification by external experts, and acceptable and reasonable benefit-sharing methods.

$\mathrm{Hu}$ et al. (2016) look at the other side of the topic: the termination of alliances. Through a multiple case study of nonprofit alliances that had been established in response to the 2008 Sichuan earthquake, they explore how and why nonprofit alliances were terminated. They address a research gap as, so far, no research on alliance failure in nonprofit-nonprofit collaboration has been conducted. The analysis shows four termination patterns among these interorganizational partnerships: death at birth, abrupt dissolution, failed transition, and evolution into independent organizations. Furthermore, political pressure, resource shortage, shortterm orientation, and leadership failure are identified as being accountable for alliance termination.

Sung's (2014) contribution examines philanthropic initiatives in Chinese higher education. Based on the notion of difficulties for domestic universities to scale up fundraising, the study of the fundraising practice, strategy, and accountability of a public institution in Asia Pacific-Pacific region assesses a best practice case- the investigated organization was one of the few institutions in the region that successfully initiated a fundraising practice. Results show the importance of establishing an appropriately staffed professional fundraising office, job training, clear fundraising goals, a focus on marketing and communication skills, and the ability to construct social networks.

\section{References}

Bräuer, S. (2015). Becoming public: Tactical innovation in the beijing anti-domestic violence movement. VOLUNTAS: International Journal of Voluntary and Nonprofit Organizations. doi:10.1007/s11266015-9610-2.

Chang, J.-N., Seetoo, D.-H., Yu, C.-M., \& Cheng, C.-Y. (2015). Relational management mechanisms for strategic alliances among nonprofit organizations. VOLUNTAS: International Journal of Voluntary and Nonprofit Organizations. doi:10.1007/s11266-015-9557-3.

Dau, M., \& Bräuer, S. (2016). Continuity and change in China's civic engagement from a 'state in society' perspective. VOLUNTAS: International Journal of Voluntary and Nonprofit Organizations. doi:10.1007/s11266-015-9669-9.

Deng, G. (2010). The hidden rules governing China's unregistered NGOs: Management and consequences. China Review, 10(1), 183-206. 
Fedorenko, I., \& Sun, Y. (2015). Microblogging-based civic participation on environment in China: A case study of the PM 2.5 Campaign. VOLUNTAS: International Journal of Voluntary and Nonprofit Organizations. doi:10.1007/s11266-015-9591-1.

Hu, M., Guo, C., \& Bies, A. (2016). Termination of nonprofit alliances: Evidence from China. VOLUNTAS: International Journal of Voluntary and Nonprofit Organizations. doi:10.1007/s11266016-9698-z.

Jackson, L., \& Adarlo, G. (2014). Bridging cultures through unpaid labor: US volunteer teachers' experiences in China's Yunnan Province. VOLUNTAS: International Journal of Voluntary and Nonprofit Organizations. doi:10.1007/s11266-014-9519-1.

Lee, C., \& Han, L. (2014). Faith-based organization and transnational voluntarism in China: A case study of the Malaysia airline MH370 incident. VOLUNTAS: International Journal of Voluntary and Nonprofit Organizations. doi:10.1007/s11266-014-9518-2.

Li, Y. (2015). Red Cross Society in Imperial China, 1904-1912: A historical analysis. VOLUNTAS: International Journal of Voluntary and Nonprofit Organizations. doi:10.1007/s11266-015-9660-5.

Ling, W. H., \& Chui, W. H. (2016). Students' willingness for future volunteering in Hong Kong. VOLUNTAS: International Journal of Voluntary and Nonprofit Organizations. doi:10.1007/s11266016-9700-9.

Nie, L., Liu, H. K., \& Cheng, W. (2016). Exploring factors that influence voluntary disclosure by Chinese foundations. VOLUNTAS: International Journal of Voluntary and Nonprofit Organizations. doi:10. 1007/s11266-016-9689-0.

Rathgeb, S., \& Gronbjerg, K. (2006). Scope and theory of government-nonprofit relations. In W. W. Powell \& R. Steinberg (Eds.), The nonprofit sector: A research handbook (pp. 221-242). New Haven: Yale University Press.

Sung, C.-I. (2014). Investigating philanthropy initiatives in Chinese higher education. VOLUNTAS: International Journal of Voluntary and Nonprofit Organizations. doi:10.1007/s11266-014-9509-3.

Wong, N. W. (2015). Advocacy coalitions and policy change in China: A case study of anti-incinerator protest in Guangzhou. VOLUNTAS: International Journal of Voluntary and Nonprofit Organizations. doi:10.1007/s11266-015-9603-1.

Wu, F., \& Yang, S. (2015). Web 2.0 and political engagement in China. VOLUNTAS: International Journal of Voluntary and Nonprofit Organizations. doi:10.1007/s11266-015-9627-6.

Xiao, M., \& Lin, H. (2015). Carrots and sticks: A case study of government-caused Danwei tradition in Chinese NGOs. VOLUNTAS: International Journal of Voluntary and Nonprofit Organizations. doi:10.1007/s11266-015-9608-9.

Xu, X., \& Liu, R. (2016). Evaluation of corporate governance in Chinese Mainland and Taiwan: a comparative study of educational foundations. VOLUNTAS: International Journal of Voluntary and Nonprofit Organizations. doi:10.1007/s11266-016-9718-z.

Yang, G. (2005). Environmental NGOs and institutional dynamics in China. The China Quarterly, 181, 46-66. doi:10.1017/S0305741005000032.

Yang, Y., Wilkinson, M., \& Zhang, X. (2014). Beyond the abolition of dual administration: The challenges to NGO governance in 21st century China. VOLUNTAS: International Journal of Voluntary and Nonprofit Organizations. doi:10.1007/s11266-014-9521-7.

Yang, B., He, Y., \& Long, W. (2015). Alienation of civic engagement in China case studies on social governance in Hangzhou. VOLUNTAS: International Journal of Voluntary and Nonprofit Organizations. doi:10.1007/s11266-015-9632-9.

$\mathrm{Yu}, \mathrm{Z}$. (2016). The effects of resources, political opportunities and organisational ecology on the growth trajectories of AIDS NGOs in China. VOLUNTAS: International Journal of Voluntary and Nonprofit Organizations. doi:10.1007/s11266-016-9686-3.

Yuanfeng, Z. (2015). Dependent interdependence: The complicated dance of government-nonprofit relations in China. VOLUNTAS: International Journal of Voluntary and Nonprofit Organizations, 26(6), 2395-2423.

Zhao, R., Wu, Z., \& Tao, C. (2016). Understanding service contracting and its impact on NGO development in China. VOLUNTAS: International Journal of Voluntary and Nonprofit Organizations. doi:10.1007/s11266-016-9714-3.

Zhou, H. (2015a). Mapping the level of development of grassroots NPOs in China. VOLUNTAS: International Journal of Voluntary and Nonprofit Organizations. doi:10.1007/s11266-015-9612-0.

Zhou, H. (2015b). Corporate philanthropy in contemporary China: A case of rural compulsory education promotion. VOLUNTAS: International Journal of Voluntary and Nonprofit Organizations, 26(4), 1143-1163. 
Zhou, H., \& Pan, Q. (2016). Information, community, and action on Sina-Weibo: How Chinese philanthropic NGOs use social media. VOLUNTAS: International Journal of Voluntary and Nonprofit Organizations. doi:10.1007/s11266-016-9685-4. 